\title{
Characterization of novel genes expressed specifically in the sexual organs of the planarian Dugesia ryukyuensis
}

\author{
SUMITAKA HASE, EMIKO KASHIWAGI, KAZUYA KOBAYASHI ${ }^{1}$, MOTONORI HOSHI ${ }^{2}$ \\ and MIDORI MATSUMOTO* \\ Department of Biological Sciences and Informatics, Keio University, Yokohama, Japan
}

\begin{abstract}
The planarian Dugesia ryukyuensis reproduces both asexually (fissiparous) and sexually (oviparous) and can switch from the asexual mode to the sexual mode. By feeding with mature Bdellocephala brunnea oviparous worms, the fissiparous worms, which do not possess sexual organs, can be converted to fully sexualized worms in a process termed sexualization. As sexualization proceeds, the sexual organs are formed uniformly and five stages (stages 1-5) of the process have been identified histologically. In order to clarify the sexualization process, we attempted to isolate the genes expressed specifically at stage 5 by the differential display method. We isolated five genes expressed in the testis and two genes expressed in the yolk gland, which is an organ specific to sexualized worms. By BLAST search, one of the testis-specific genes was coded as testis-specific $\alpha$-tubulin and two yolk gland-specific genes are similar to ribosephosphate pyrophosphokinase I and F-box/SPRY-domain protein 1. Drs1, Drs2 and Drs3 were expressed in spermatocytes and spermatids from the early stage of spermatogenesis and Drs4 and Drs 5 were expressed in spermatogonia, spermatocytes and spermatids. These genes are useful markers for elucidating the sexualization process.
\end{abstract}

KEY WORDS: planarian, sexualization, point-of-no-return, testis, yolk gland

Living organisms have established unique reproductive systems to multiply and sustain their species. Two types of reproduction evolved, namely, asexual and sexual (Bell, 1982). Planarians (Platyhelminthes, Turbellaria, Tricladida) reproduce both asexually (fissiparous) and sexually (oviparous) and they can switch from one mode of reproduction to the other (Curtis, 1902; Curtis and Schulze, 1924; Kenk, 1937; Kenk, 1940). An experimental system was established in which sexually mature worms of the oviparous species Bdellocephala brunnea are fed to fissiparous Dugesia ryukyuensis worms in order to elucidate the mechanisms underlying the conversion from an asexual mode of reproduction to a sexual mode of reproduction (Kobayashi et al., 1999; Hoshi et al., 2003). This experimental sexualization is apparently triggered by a sexualizing substance(s) contained in oviparous planarians (Grasso and Benazzi, 1973; Benazzi, 1973; Grasso et al., 1975; Sakurai, 1981; Kobayashi et al., 1999). The sexualization process is divided histologically into five stages (stages 1-5). As sexualization proceeds, the fissiparous worms form mature sexual organs. A pair of ovaries appears behind the head at stage 1 and mature as sexualization proceeds. The primordial testes, which are located on the dorsal side, emerge at stage 3 , spermatocytes and spermatids can be observed at stage 4 and many sperm are detectable in the testes at stage 5 (Kobayashi and Hoshi, 2002). Differentiation of the copulatory apparatus starts at the end of stage 3 and a genital pore opens on the ventral surface at stage 4 . The yolk glands appear at stage 4 and develop with sexualization. It was demonstrated that worms in stages 1 and 2 of the sexualization process could return to the fissiparous state if feeding on $B$. brunnea was stopped. However, worms from stage 3 onward could not return to the fissiparous state. Therefore, a time-point, referred to as the point-of-no-return, exists between stages 2 and 3 (Kobayashi et al., 1999). This suggests that from the point-of-no-return onward, worms produce sexualizing substance(s) in their own bodies in order to maintain their sexualized condition (Kobayashi et al., 2002). Accordingly, it is important to understand the acquisition of sexuality and the sexualizing events in detail after the point-of-no-return.

Abbreviations used in this paper: Drs, Dugesia ryukyuensis sexual organ specific gene.

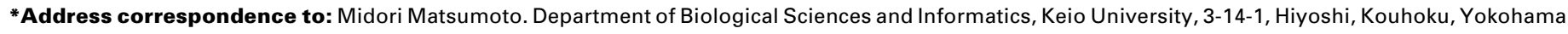
223-8522, Japan. Fax: +81-45-566-1448. e-mail: mmatsumo@bio.keio.ac.jp

1 Present address: Animal Evolutionary Ecology, Zoological Institute, University of Tübingen, Auf Der Morgenstelle 28, 72076 Tübingen, Germany. 2 Present address: The University of the Air, 2-11, Wakaba, Mihama-ku Chiba 261-8586, Japan.
} 
During the sexualizing process, the development of the ovary and the opening of the genital pore can be observed, but development of the testes and other sexual organs could be detected only histologically. It is difficult to categorize worms into each stage by external observation and especially after the point-of-no-return the only external feature is the genital pore at stage 4. Dryg was the first cDNA characterized as being expressed in the yolk gland, which is one of the specific organs for oviparous worms, of worms at stage 5. Dryg expression started in neoblast-like cells in worms at stage 3 , so this gene is a good marker for analyzing the sexualization process after the point-of-no-return (Hase et al., 2003). The genes expressed in worms at stage 5 are molecular markers of the sexualizing process.

Recently, to characterize the sexualization process by use of the molecular markers, the worms at stage 5 expressed sequence tag database (the sexualized planarian EST-DB: http://planaria.bio.keio.ac.jp/planaria/) was constructed and opened as an online resource (Ishizuka et al., in press). It contains 3,077 expressed clusters, but this is not enough to cover all the genes expressed in the worms at stage 5 . For a detailed study, many of the markers for sexual organs are essential. In this study, to obtain the trace of specific genes in the worms at stage 5 using the differential display method, we tried to isolate genes specific for worms at stage 5 . We successfully isolated seven genes that are expressed in the testes and yolk glands, both of which differentiate after the point-of-noreturn.

\section{Results}

\section{Isolation of specific genes at stage 5}

Seven specific genes (Drs1-7) in worms at stage 5 were obtained by the comparison between fissiparous worms and worms at stage 5 with the differential display method. These genes were examined for stage 5 -specificity by Northern blot hybridization using RNAs extracted from fissiparous worms and worms at stage 5 (Fig. $1 \mathrm{~A})$. The results revealed a single band detected specifically in worms at stage 5 . The sizes of of Drs1, Drs2, Drs3, Drs4, Drs5, Drs6 and Drs7mRNAs were predicted to be $0.7 \mathrm{~kb}, 1.1 \mathrm{~kb}, 2.0 \mathrm{~kb}, 2.1 \mathrm{~kb}, 0.9 \mathrm{~kb}, 1.4 \mathrm{~kb}$ and $1.4 \mathrm{~kb}$, respectively. Their full-length cDNAs were isolated and sequenced. The cDNA sequences have been deposited in GenBank under accession numbers AB284772 (Drs1), AB284773 (Drs2), AB284774 (Drs3), AB284775 (Drs4), AB284776 (Drs5), AB284777 (Drs6) and AB284778 (Drs7). Drs2, Drs3, Drs4, Drs5, Drs6 and Drs7 encoded a predicted polypeptide of $272,534,584,239,316$ and 352, amino acid residues, respectively. Since Drs1 did not appear to encode a significant open reading frame (ORF), this gene may not be translated into a polypeptide and may belong to a non-coding RNA gene (ncRNA), which could act as the developmental timer of protein expression.

\section{Expression stage of Drs1-7 in sexualization}

RT-PCR was performed to determine stage-specificity during sexualization (Fig. 1B). Amplifications of Drs1, Drs2, Drs4 and Drs6 were recognized only in the RNA extracted from worms at stage 5. On the other hand, the Drs5and Drs7 and Drs3 fragments were amplified slightly at stage 3 and stage 4 , respectively and increased as sexualization proceeded. These genes were expressed after the point-of-no-return and they should be good gene markers for sexualization.

\section{Histological analysis of Drs1-7 on sexualized worms}

To analyze the spatial expression patterns of Drs 1-7, wholemount in situ hybridization was performed with worms at stage 5 . The expression of Drs $1-5$ was detected specifically as two lines on the dorsal side, which could be regions of the testes (Fig. 2AE). The expression of Drs6 and Drs7 was detected specifically in the region of the yolk glands, which is along the ventral nerve system (Fig. 3A and B).

To investigate this expression more precisely, section in situ hybridization was performed. Drs1, Drs2 and Drs3 were expressed in the testes at the level of spermatocytes and spermatids (Figs. 2F, G and $\mathrm{H}$ ) and were revealed by hematoxylin and eosin

A
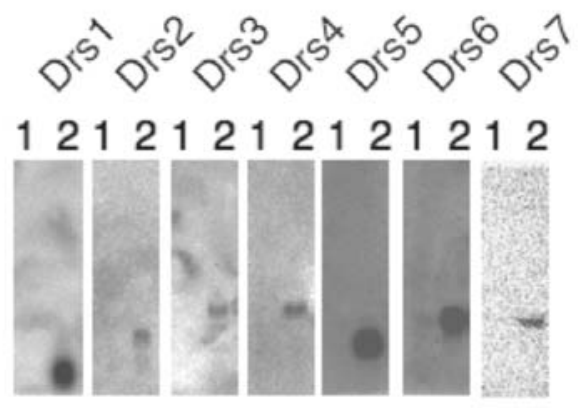

B
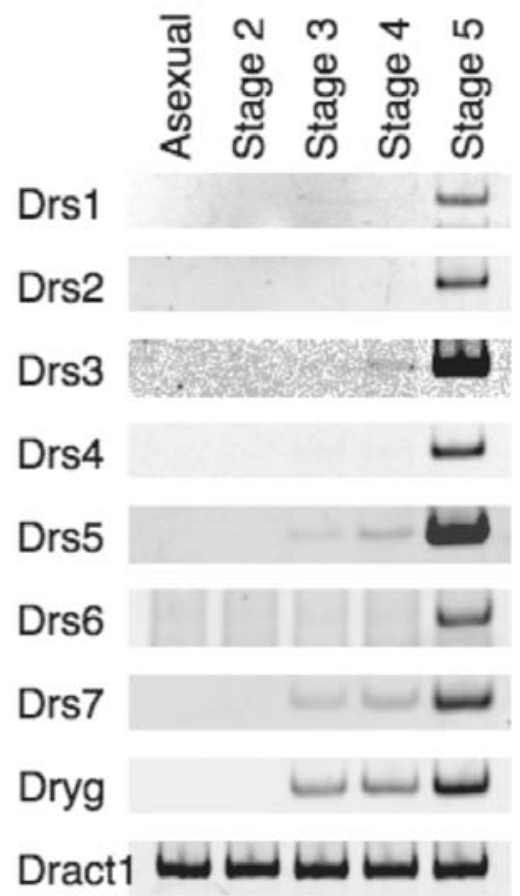

Fig. 1. Sexualized worm-specific expression of Drs1-7. (A) Northern hybridization with the fissiparous worm (1) and the worm of stage 5 (2). (B) RT-PCR for stage-specificity during the sexualization process (fissiparous, stage2, stage3, stage4 and stage5). 

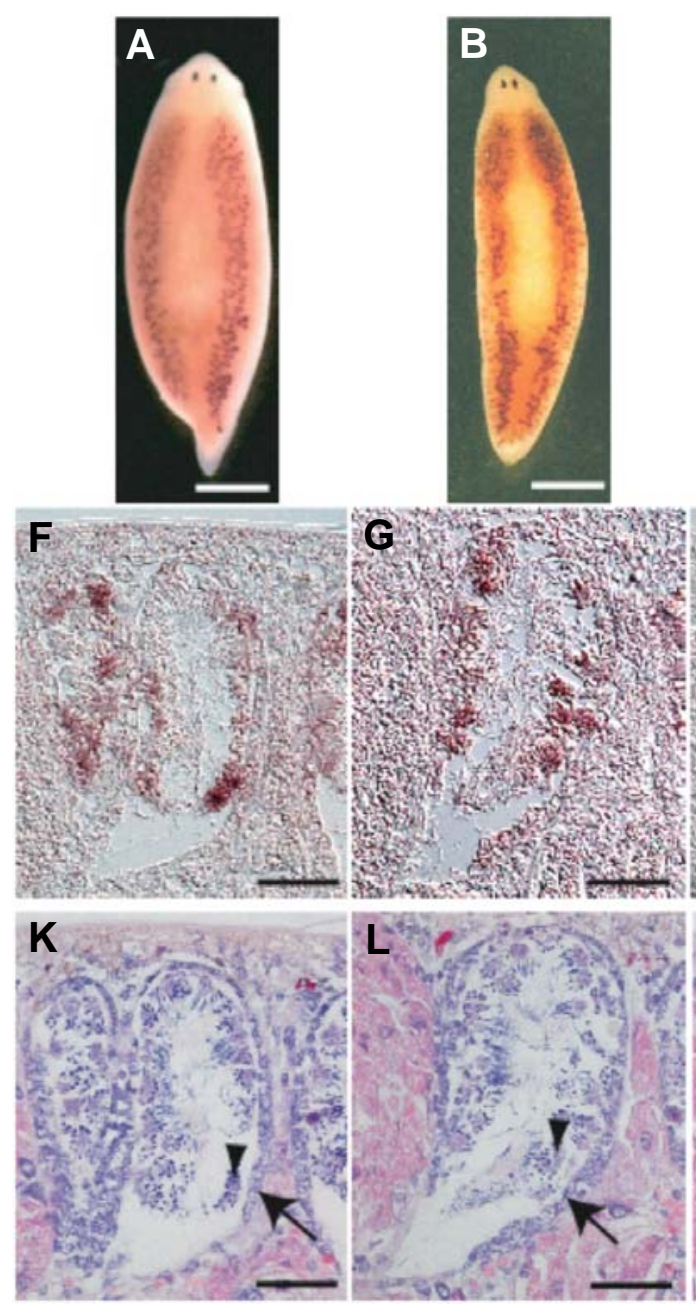
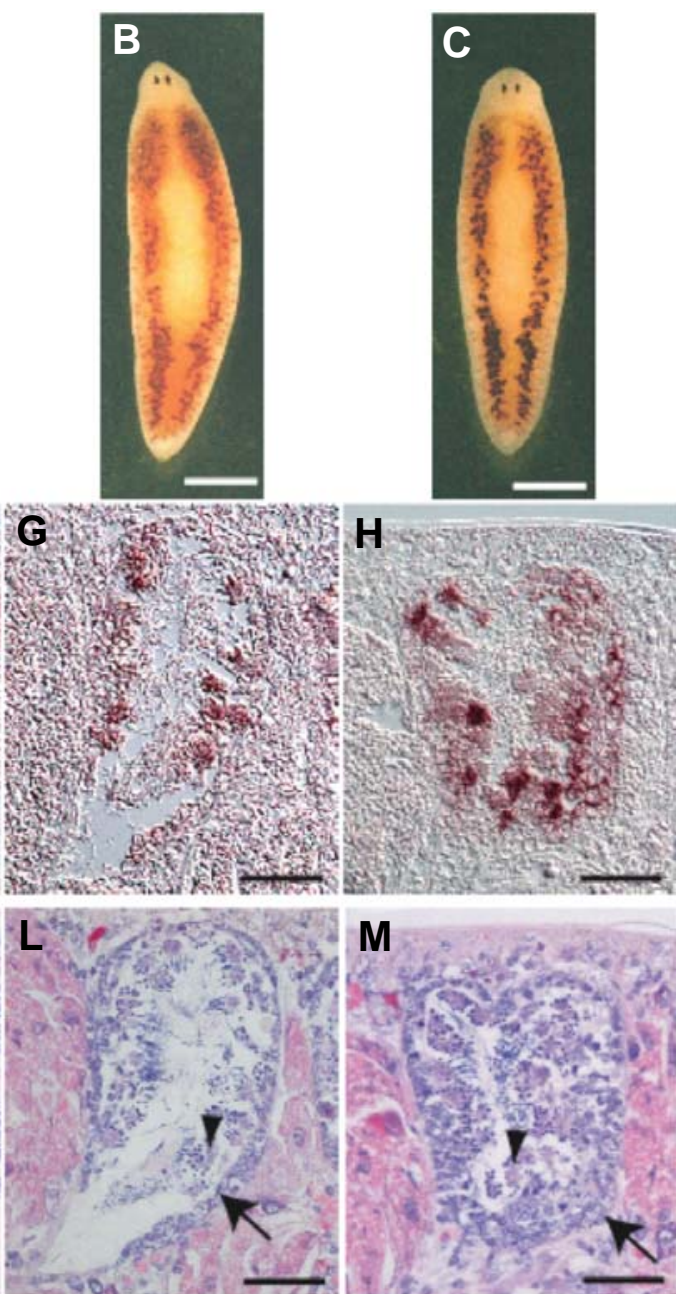
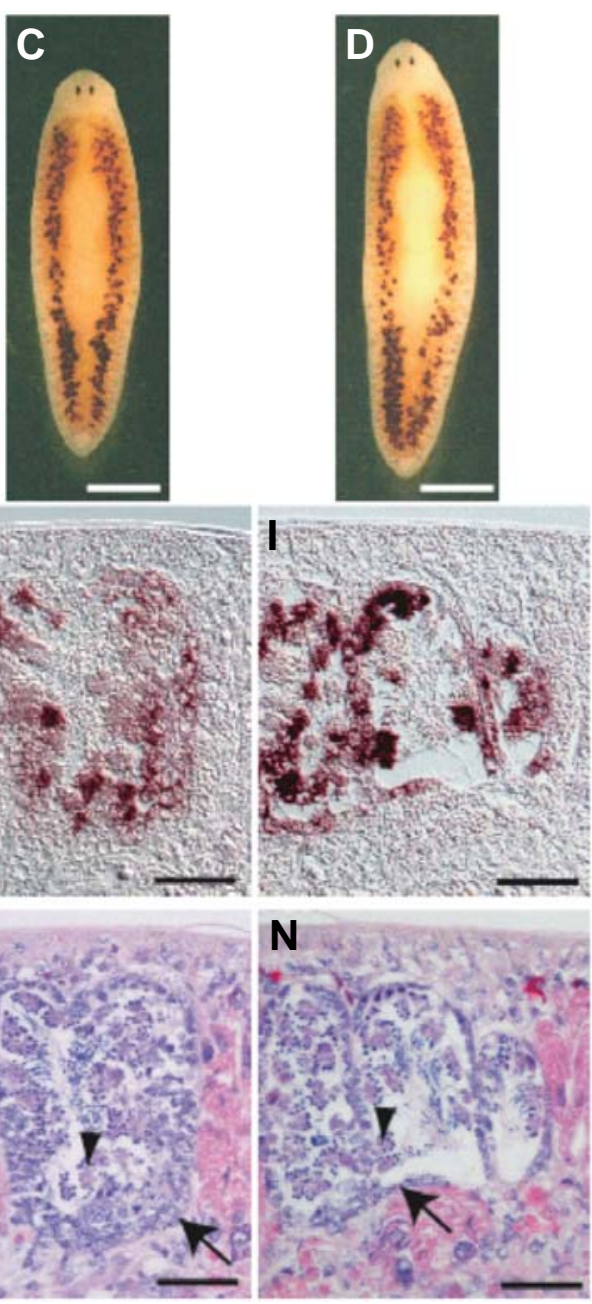
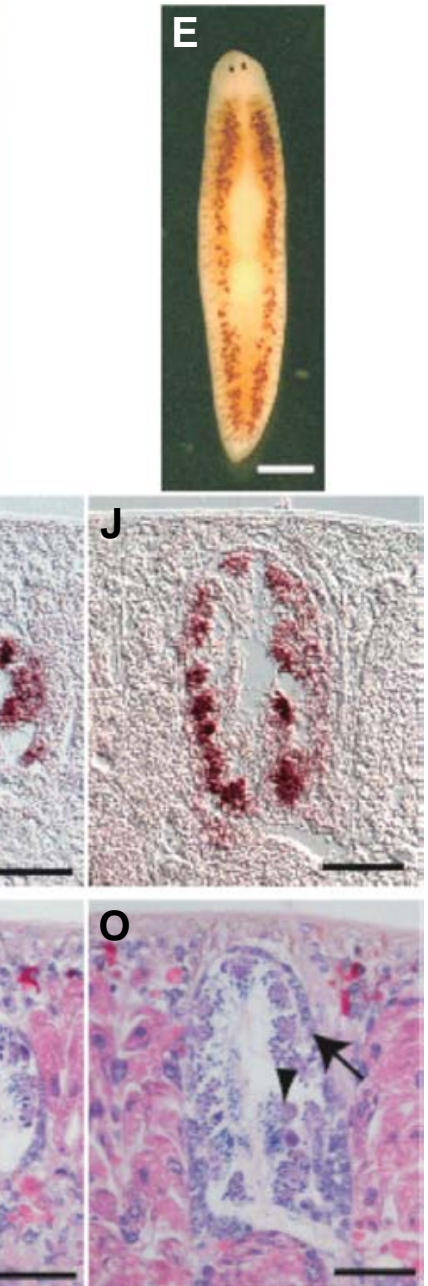

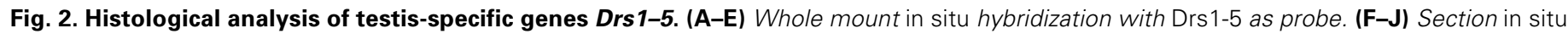

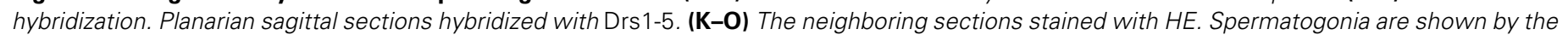
arrow and spermatocytes are shown by the arrowhead. Scale bars, (A-E) $1 \mathrm{~mm}$; (F-O) $50 \mu \mathrm{m}$.

(HE) staining (Figs. 2K, L and M). No signal was detected in the spermatogonia. The signals of Drs 4 and Drs5 were expressed in the testes at the levels of spermatogonia, spermatocytes, spermatids and developing spermatids (Fig. $2 \mathrm{I}$ and $\mathrm{J}$ ), as revealed by HE staining (Fig. 2N and O). The signals of Drs6 and Drs7 appeared in whole yolk gland cells (Fig. 3C and D) and were revealed by HE staining (Fig. 3E and $\mathrm{F}$ ).

\section{Homology search of Drs1-7}

By the BLAST search, four of them (Drs1, Drs2, Drs4 and Drs5) were not included in any database and were recognized as novel genes. Genes of Drs3, Drs6 and Drs7 were annotated. By searching for them in the sexualized planarian EST-DB, it was found that Drs3 was highly similar to DrC-00131, annotated testes-specific $\alpha$-tubulin isoform ( $E$-value $<6 E$-151). Drs6 was highly similar to DrC-00052, annotated human ribose-phosphate pyrophosphokinase I (E-value < 4E-85) and Drs7 was highly similar to DrC00667, annotated mouse F-box/SPRY-domain protein 1 ( $E$-value $<5 E-31)$. Drs6 and Drs 7 were matched completely to DrC-00052 and DrC00667, respectively and are known genes.
While this EST-DB included 7 clusters of $\alpha$-tubulin gene, using the Clustal W program to analyze the differences between Drs3 and DrC-00131, it was matched with only $53.5 \%$ identity at the amino acid level and Drs3 is a novel gene in the $D$. ryukyuensis genome. DrC-00052 and DrC00667 were present in 12 genes and 9 genes in the EST-DB, suggesting that they are expressed abundantly, but the others were not included in the EST-DB. Therefore, these results showed that the differential display method is a practical method for cloning the many markers for oviparous worms (or at stage 5).

\section{Discussion}

In this study, we could identify seven genes, including five novel genes."Drs3 is annotated as $\alpha$-tubulin and the extremely homologous region includes: the diagnostic portion, which is conserved exclusively within the $\alpha$-tubulin subclass; the potential GTP-binding site (GGGTGSG) required for the polymerization of the $\alpha$ - and $\beta$-chains (Sternlicht et al., 1987). As the sexualized planarian EST-DB showed seven clusters of encoded $\alpha$-tubulin, 


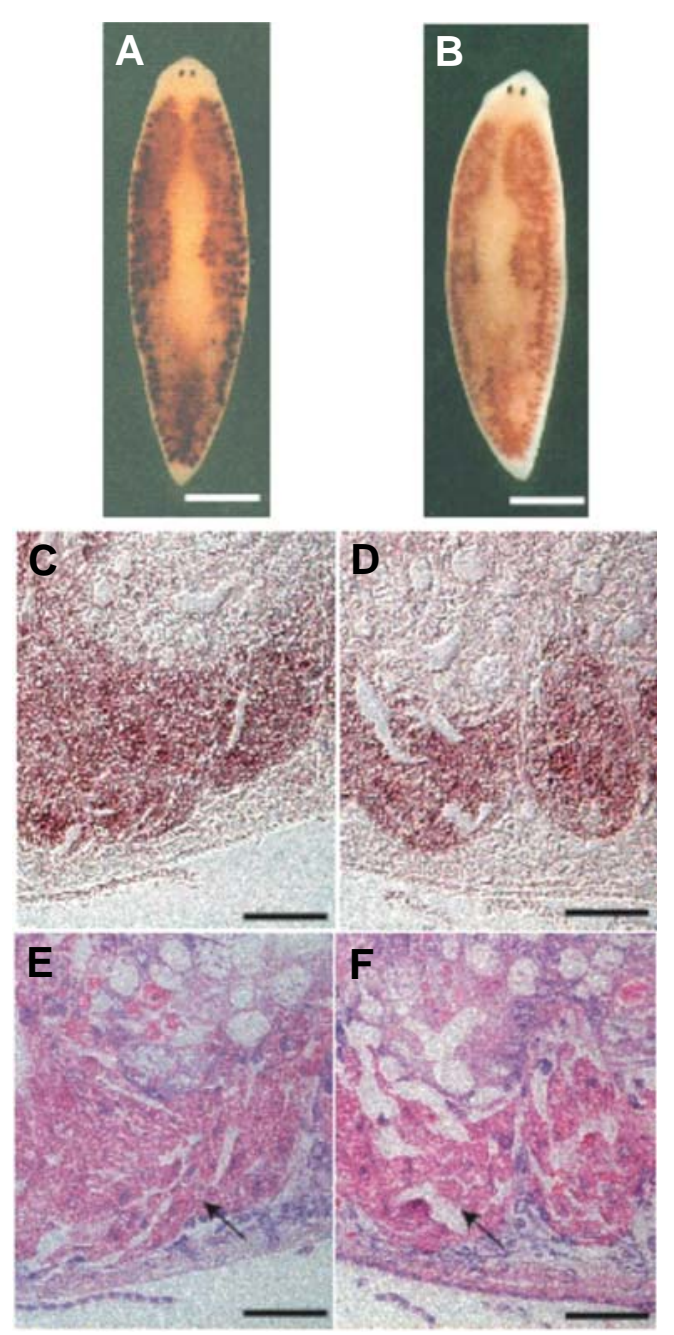

Fig. 3. Histological analysis of yolk gland-specific genes Drs6 and Drs7. (A,B) Whole mount in situ hybridization with Drs, Drs7 as probes, respectively. (C,D) Section in situ hybridization. Planarian sagittal sections hybridized with Drs6 and Drs7, respectively. (E,F) The neighboring sections stained with HE. Yolk gland cells are shown by the arrow. Scale bars: $(A, B) 1 \mathrm{~mm},(C-F) 50 \mu \mathrm{m}$.

the tubulin multi-gene family exists in the $D$. ryukyuensis genome, but Drs3 is different from the seven cluster genes. Few data are available about the $\alpha$-tubulin genes in the Tricladida. Molecular cloning involves an $\alpha$-tubulin gene in Schmidtea polychroa as SpTub-1 (AF516884) and a partial $\alpha$-tubulin cDNA in Schmidtea mediterranea (AF112360). SpTub-1 is a testis-specific tubulin isoform and is expressed in spermatogonia, spermatocytes and spermatids (Salvetti et al., 2002, Simoncelli, et al., 2003), while the $\alpha$-tubulin in $S$. mediterranea is expressed in the epithelium but not in testes (Sanchez and Newmark, 1999). The expression pattern of SpTub-1 is very similar to that of Drs3, but using the Clustal W program to analyze the differences between Drs3 and other $\alpha$-tubulins, the sequence similarity with the $\alpha$-tubulin in $S$. mediterranea is only $45.71 \%$. And the C-terminal region of Drs3 contained a long insertion sequence. These findings showed that Drs3 is not a homolog for the SpTub-1 gene. Almost all animals express some testis-specific tubulin, which is a major protein in the sperm tail for sperm motility. The Drs3 product could also act in sperm tail movement.

One of the annotated genes was a ribose-phosphate pyrophosphokinase (RPPP; EC 2.7.6.1) isoform, which is catalyzed from MgATP and ribose-5-phosphate in the synthesis of virtually all nucleotides, as well as being an important regulator of rates of the de novo pathways of purine and pyrimidine nucleotide synthesis. In mammals, one of two RPPP isoforms is detected in almost all tissues and the other isoform is detected in the testes. In the planarian, the yolk gland has a function to supply the egg. Then, the yolk gland-specific RPPP isoform might be expressed.

Drs7 is annotated as F-box/SPRY-domain protein 1, which is known as a synaptic protein in several animals. Many F-box proteins are target recognition subunits of SCF (Skp, Cullin, Fbox) ubiquitin-ligase complexes. And FSN-1, the encoded F-box/ SPRY-domain protein 1 in Caenorhabditis elegans, is required in presynaptic neurons for the restriction and/or maturation of synapses and provides a localized signal to attenuate presynaptic differentiation. It is not understood how the nervous system regulates the development or function of the yolk gland in the planarian.

Though Drs1, Drs2 and Dr 4 stage 5-specific expression genes, Drs 1 and Drs2 were transcribed only in spermatocyte and Drs4 was transcribed in spermatogonia and spermatocyte. Since spermatogonia appeared from stage 3 in this sexualization system, Drs 4 might not be related to spermatogenesis, but might be related to the maintenance of testes.

Earlier, we constructed the sexualized planarian EST-DB containing 3077 expressed clusters of worms at stage 5 (Ishizuka et al., in press). In this study, we obtained the seven specific genes in worms at stage 5, including five unknown genes using the differential display method. Almost none of the 3077 clusters in EST-DB can be used as a marker for sexual organs and the rate of cloning markers for sexual organs with the differential display method is higher than that for the EST-DB. It was shown that this method is more effective for isolating genes that are transcribed at a low level, which may nevertheless be important.

\section{Experimental Procedures}

\section{Animals}

We used fissiparous worms and worms from stages 2-5 of the $\mathrm{OH}$ strain of $D$. ryukyuensis. The sexualizing system followed Kobayashi's method (Kobayashi et al., 1999). The animals were maintained at $20^{\circ} \mathrm{C}$ in dechlorinated tap water.

\section{Isolation of stage 5-specific cDNA}

Total RNA was isolated from fissiparous worms or worms at stage 5 that were starved for 1 week. To identify the genes that are expressed specifically in worms at stage 5, we employed differential display techniques using RNA Image Kits (GenHunter). A partial cDNA of Drs 1-7 was obtained using the primers $\mathrm{H}-\mathrm{T} 11 \mathrm{G}$ and $\mathrm{H}-\mathrm{AP} 5, \mathrm{H}-\mathrm{T} 11 \mathrm{C}$ and $\mathrm{H}-\mathrm{AP} 4, \mathrm{H}$ T11A and H-AP4, H-T11C and H-AP9, H-T11A and H-AP9, H-T11C and $\mathrm{H}-\mathrm{AP} 14$ and $\mathrm{H}-\mathrm{T} 11 \mathrm{G}$ and $\mathrm{H}-\mathrm{AP} 12$, respectively. The full length of these genes were obtained by screening a cDNA library in Lambda ZAP II (Stratagene) or using a SMART RACE kit (Clontech) following the manufacturer's instructions.

\section{Northern hybridization}

For Northern blot analysis (Sambrook et al., 1989), we separated 7.5 $\mathrm{g}$ of total RNAs on $1 \%$ agarose gel containing formaldehyde and trans- 
ferred them to a positively charged nylon membrane (Pall Biodyne B). Northern blot hybridization was carried out under the following conditions: hybridization, $4 \times$ SSC, $0.12 \mathrm{mg} / \mathrm{ml}$ salmon sperm DNA, $0.2 \%$ SDS, $5 \times$ Denhardt's solution, $50 \%$ formamide at $42^{\circ} \mathrm{C}$ for $16 \mathrm{~h}$; washing, $2 \times$ SSC$0.1 \%$ SDS at $50^{\circ} \mathrm{C}$ for $10 \mathrm{~min}, 0.2 \times$ SSC $-0.1 \%$ SDS at $50^{\circ} \mathrm{C}$ for 1 th, repeated once. The cDNAs were labeled with $\left[\alpha-{ }^{32} \mathrm{P}\right] \mathrm{dCTP}(3000 \mathrm{Ci} /$ $\mathrm{mmol}$ ) using a random prime labeling system (Amersham Pharmacia Biotech) for hybridization probes. After washing, the blots were analyzed using a BAS5000 Bio-Image Analyzer (Fuji Photo Film). Dract1 (GenBank accession number AB292462, actin in D. ryukyuensis) was used as internal control and Dryg (GenBank accession number AB090278), which is expressed in the yolk gland, was used as positive control.

\section{In situ hybridization and histology}

Whole-mount in situ hybridization was performed in accordance with the protocols described by Umesono et al. (1997) and Agata et al. (1998). Section in situ hybridization was performed as described by Kobayashi et al. (1998). Sense and antisense riboprobes were prepared by in vitro transcription using RNA polymerase with digoxigenin-UTP (Roche). For histology, the sections were stained with $\mathrm{HE}$.

\section{Polymerase chain reaction and cDNA cloning}

RT-PCR analysis was performed using total RNAs from fissiparous worms and worms from stages $2-5$ and specific primers as follows:

$\begin{array}{lll}\text { Drs1 } & \mathrm{F} & \text { 5'-CCATCAGGGACGAATATTCCAG-3' } \\ & \mathrm{R} & \text { 5'-TGAGTATCTTTAGTTGAAATAC-3', } \\ \text { Drs2 } & \mathrm{F} & \text { 5'-TCATATGGAATCAAATATTACACCAGG-3', } \\ & \mathrm{R} & \text { 5'-CACGTTGAGATTATGCGATACTGCATAG-3', } \\ \text { Drs3 } & \mathrm{F} & \text { 5'-CTCGTCTGTTGAGTTAACAGATC-3', } \\ & \mathrm{R} & \text { 5'-TGTGAAGTGGCCTCGTGCAAAG-3', } \\ \text { Drs4 } & \mathrm{F} & \text { 5'-AGAAAAACTTTGAAGATGACACCTC-3' } \\ & \mathrm{R} & \text { 5'-AAGTATCTCCTGTTCCTTCATTGCCACG-3' } \\ \text { Drs5 } & \mathrm{F} & \text { 5'-GACAGTAACTGTTGGAACGTC-3' } \\ & \mathrm{R} & \text { 5'-CGTATTTCTGGCATATCTAAGAGC-3' } \\ \text { Drs6 } & \mathrm{F} & \text { 5'-GTCATCCGCTCGTATCACAGCAG-3' } \\ & \mathrm{R} & \text { 5'-GGCCACACGTTCTGCACTGGTAAC-3' } \\ \text { Drs7 } & \mathrm{F} & \text { 5'-GACATCATTGCCGATATAAT-3' } \\ & \mathrm{R} & \text { 5'-ATGACTCAAATACGAGCATA-3' } \\ \text { Dryg } & \mathrm{F} & \text { 5'-TTGGACGGATTTCTATTCTATGCC-3' } \\ & \mathrm{R} & \text { 5'-CACTGGGTTTCTGATCTCTTTCG-3' } \\ \text { Dract1 } & \mathrm{F} & \text { 5'-CAGAAATGAGAACAGCATCAGC-3' } \\ & \mathrm{R} & \text { 5'-CAATTCCAGGTCCAGATTGTC-3' }\end{array}$

The annealing temperature was $55^{\circ} \mathrm{C}$ for Drt1, Drt5, Drt6 and Drt7 and $65^{\circ} \mathrm{C}$ for Drt2, Drt3 and Drt4. In all, 36 cycles were performed. Control reactions were performed in the absence of reverse transcripts.

\section{Acknowledgements}

This work was supported, in part, by the Precursory Research for Embryonic Science and Technology (PRESTO), Japan Science and Technology Corporation.

\section{References}

AGATA, K., SOEJIMA, Y., KATO, K., KOBAYASHI, C., UMESONO, Y. and WATANABE, K. (1998). Structure of the planarian central nervous system (CNS) revealed by neuronal cell markers. Zool Sci. 15: 433-440.

BELL, G. (1982). The Masterpiece of Nature: The Evolution and Genetics of Sexuality. University of California Press, Berkeley CA.

BENAZZI, M. (1973). Further observations on the induction of sexuality in agamous planarian strains. Boll Zoll. 40: 393-397.

CURTIS, W.C. (1902). The life history, the normal fission and the reproductive organs of Planaria maculata. Proc Boston Soc Nat Hist. 30: 515-559.

CURTIS, W.C. and SCHULZE, L.M. (1924). Formative cells of planarians. Anat Rec. 29:105.

GRASSO, M. and BENAZZI M (1973). Genetic and physiologic control of fissioning and sexuality in planarians. J Embryol Exp Morphol. 30: 317-328.

GRASSO, M., MONTANARO, L. and QUAGLIA, A. (1975). Studies on the role of neurosecretion in the induction of sexuality in a planarian agamic strain. $J$ Ultrastruct Res. 52: 404-408.

HASE, S., KOBAYASHI, K., KOYANAGI, R., HOSHI, M. and MATSUMOTO, M. (2003). Transcriptional pattern of a novel gene, expressed specifically after the point-of-no-return during sexualization, in planarian. Dev Genes Evol.212: 585592

HOSHI, M., KOBAYASHI, K., ARIOKA, S., HASE, S. and MATSUMOTO M (2003). Switching from asexual to sexual reproduction in the planarian Dugesia ryukyuensis. Integ Comp Biol. 43: 242-246.

ISHIZUKA, H., MAEZAWA, T., KAWAUCHI, J., NODONO, H., HIRANO, Y., NISHIMURA, O., NAKAGAWA, H., SEKII, K., TASAKA, K., TARUI, H., AGATA K., HOSHI, M., KOBAYASHI, K., SAKAKIBARA, Y. and MATSUMOTO, M (2007). The Dugesia ryukyuensis database as a molecular resource for studying on switching of reproductive system. Zool Sci. in press

KENK, R. (1937). Sexual and asexual reproduction in Euplanaria tigrina (Girard). Biol Bull. 73: 280-294

KENK, R. (1940). The reproduction of Dugesia tigrina (Girard). Amer Nature. 74 $471-475$

KOBAYASHI, C., KOBAYASHI, S., ORII, H., WATANABE, K. and AGATA, K (1998). Identification of two distinct muscles in the planarian Dugesia japonica by their expression of myosin heavy chain genes. Zool Sci. 15: 861-869

KOBAYASHI, K., KOYANAGI, R., MATSUMOTO, M., CABRERA, J.P. and HOSHI, M. (1999). Switching from asexual to sexual reproduction in the planarian Dugesia ryukyuensis: Bioassay system and basic description of sexualizing process. Zool Sci. 16: 291-298.

KOBAYASHI, K. and HOSHI, M. (2002). Switching from asexual to sexual reproduction in the planarian Dugesia ryukyuensis: Change of the fissiparous capacity along with the sexualizing process. Zool Sci. 19: 661-666.

KOBAYASHI, K., ARIOKA, S., HASE, S. and HOSHI, M. (2002). Signification of the sexualizing substance produced by the sexualized planarians. Zool Sci. 19: 667-672.

SAKURAI, T. (1981). Sexual induction by feeding in an asexual strain of the freshwater planarian, Dugesia japonica japonica. Annot Zool Jap. 54: 103-112.

SANCHEZ ALVARADO, A. and NEWMARK, P.A. (1999). Double-stranded RNA specifically disrupts gene expression during planarian regeneration. Proc Natl Acad. Sci USA. 96: 5049-5054.

SALVETTI, A., LENA, A., ROSSI, L., DERI, P., CECCHETTINI, A., BATISTONI, R. and GREMIGNI, V. (2002). Characterization of DeY1, a novel Y-box gene specifically expressed in differentiating male germ cells of planarians. Gene Expression Patterns. 2: 195-200.

SIMONCELLI, F., SORBOLINI, S., FAGOTTI, A., ROSA, I.D., PORCEDDU, A. and PASCOLINI, R. (2003). Molecular characterization and expression of a divergent $\alpha$-tubulin in planarian Schmidtea polychroa. Biochim Biophys Acta. 1629 26-33.

STERNLICHT, H., YAFFE, M.B. and FARR GW (1987). A model of the nucleotidebinding site in tubulin. FEBS Lett. 214: 226-235.

UMESONO, Y., AGATA, K. and WATANABE, K. (1997). A planarian orthopedia homolog is specifically expressed in the branch region of both the mature and regenerating brain. Dev Growth Differ. 39: 723-727.

Received: 27th December 2006 Reviewed by Referees: 26th January 2007 Modified by Authors and Accepted for Publication: 20th March 2007 Published Online: 16th May 2007 


\section{Previously published, related Int. J. Dev. Biol. articles of interest}

See our Special Issue on Mammalian Reproduction and Development edited by Brigid Hogan at: http://www.ijdb.ehu.es/web/contents.php?vol=45\&issue=3

Hox and ParaHox genes in Nemertodermatida, a basal bilaterian clade

Eva Jiménez-Guri, Jordi Paps, Jordi García-Fernández and Emili Saló

Int. J. Dev. Biol. (2006) 50: 675-679

P450 aromatase expression in the temperature-sensitive sexual differentiation of salamander (Hynobius retardatus) gonads

Natsuko Sakata, Yoichiro Tamori And Masami Wakahara

Int. J. Dev. Biol. (2005) 49: 417-425

Molecular markers for germ cell differentiation in the demosponge Suberites domuncula

Sanja Perovic-Ottstadt, Helena Cetkovic, Vera Gamulin, Heinz C. Schroder, Klaus Kropf, Claire Moss, Michael Korzhev, Barbel Diehl-Seifert, Isabel M. Muller and Werner E.G. Muller

Int. J. Dev. Biol. (2004) 48: 293-305

Planarian pharynx regeneration revealed by the expression of myosin heavy chain-A.

Tomoko Sakai, Kentaro Kato, Kenji Watanabe and Hidefumi Orii

Int. J. Dev. Biol. (2002) 46: 329-332 


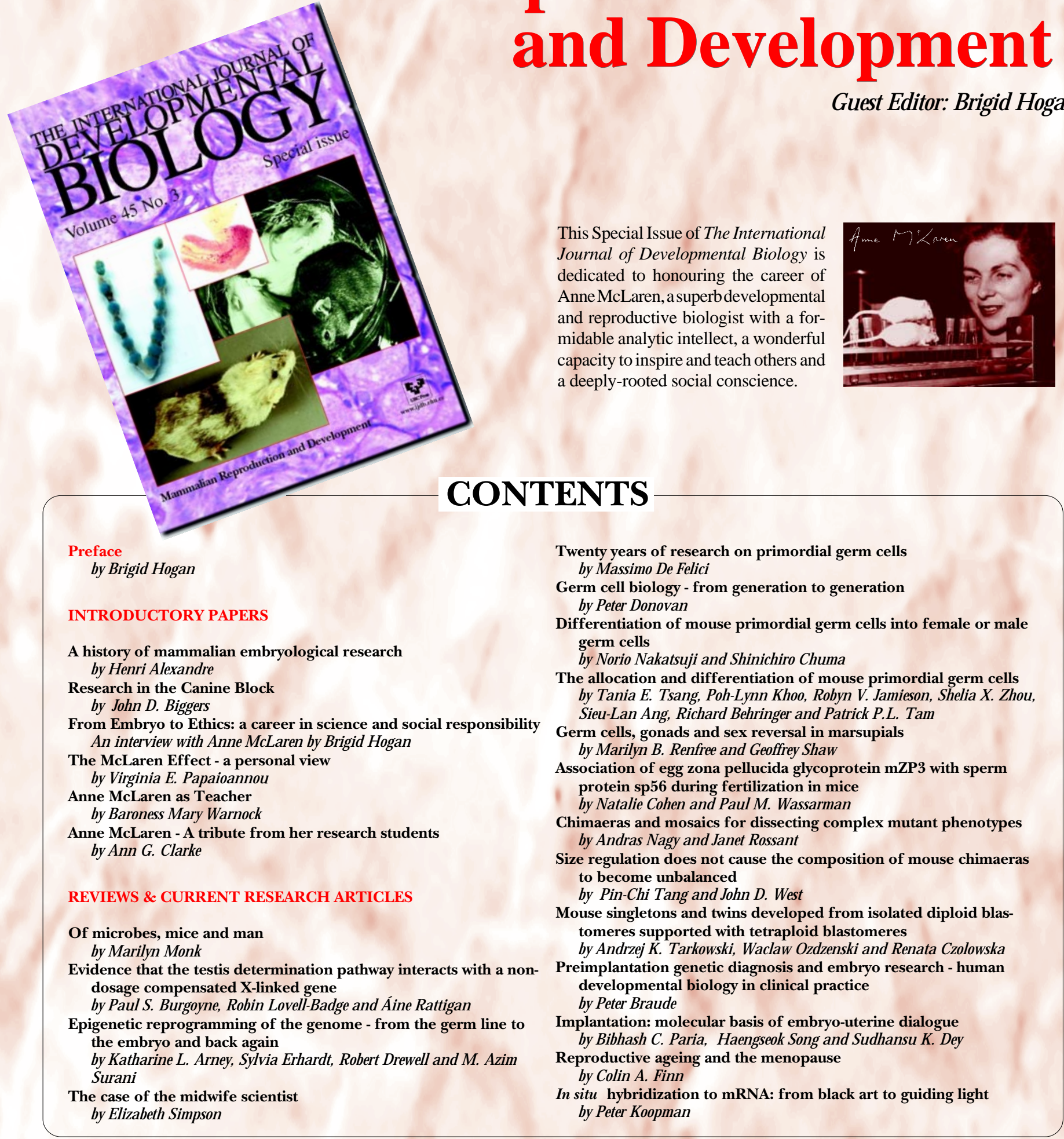

\section{ORDER FORM}

I would like to order ___ cop(y/ies) of the Int. J. Dev. Biol. Special Issue “Mammalian Reproduction and Development” (Vol. 45, № 3) at US\$ 90 or Euro $€ 70$ per copy (including post and packaging). Total to be charged: US\$ / Euro $€$ (please specify currency)

\section{ORDER BY}

$\checkmark$ Web: http://www.intjdevbiol.com

$\checkmark$ E-mail: ijdb@ehu.es (include the information indicated above)

$\checkmark$ FAX: +34-94-601-3266

$\checkmark$ POST: to the address shown beside
The International Journal of Developmental Biology

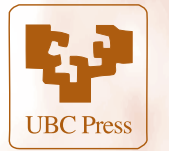

UBC Press - Faculty of Medicine

University of the Basque Country, E-48940 Leioa, Vizcaya,

SPAIN 